特集 未破裂脳動脈瘤のコイル塞栓術

\title{
ダブルマイクロカテーテル法を使用した未破裂脳動脈瘤 に対する瘤内コイル塞栓術の治療成績
}

\author{
毛利 正直, 内山 尚之, 渡邊 卓也, 見崎 孝一 \\ 林康彦, 林裕, 演田潤一郎
}

\section{Coil Embolization for Unruptured Aneurysms Using Double Microcatheter Technique}

\author{
Masanao Mohri, M.D., Naoyuki Uchiyama, M.D., Takuya Watanabe, M.D., \\ Kouichi Misaki, M.D., Yasuhiko HaYashi, M.D., Yutaka HaYashi, M.D., and \\ Jun-Ichiro HaMADA, M.D.
}

Department of Neurosurgery, Graduate School of Medical Science, Kanazawa, Ishikawa, Japan

Summary: We evaluated the radiologic and clinical outcome of unruptured intracranial aneurysms treatment by using double microcatheters into the aneurysm. Between October 2006 and December 2009, 30 patients with 30 aneurysms were treated, including 12 patients treated by using double microcatheters and 18 patients treated by using a single microcatheter. The volume embolization ratio (VER) — percentage of the coil volume occupying the aneurysmal lumen-was used as an index to evaluate the radiologic results. The VER of aneurysms treated with doublemicrocatheter technique was $25.2 \pm 4.8 \%$, and the VER of aneurysms treated with the singlemicrocatheter technique was $21.6 \pm 3.9 \%(\mathrm{P}<0.05)$. There was 1 ischemic complication in the single-microcatheter technique group, and no complications in the double-microcatheter technique group.

Although in the aneurysms with a long aneurysmal diameter/short aneurysmal diameter (L/S) ratio less than 1.5, there were no significant differences between the 2 groups, in the aneurysms with a L/S ratio of 1.5 or greater, the VER of aneurysms treated with the double-microcatheter technique was $27.6 \pm 4.3 \%$, and the VER of aneurysms treated with single-catheter technique was $19.7 \pm 3.4 \%(\mathrm{P}<0.05)$. The advantage of the double-microcatheter technique is that placing 2 microcatheters into the aneurysm allowed 2 coils to achieve a stable coil configuration before either coil was detached.

The double microcatheter technique is an effective and safe treatment for unruptured aneurysms.

\footnotetext{
Key words:

- cerebral aneurysm

- endovascular treatment

- double microcatheter technique

- volume embolization ratio

$\cdot$ detachable coil
}

Surg Cereb Stroke

(Jpn) 39: 393-397, 2011

金沢大学 脳神経外科(受稿日 2010.9.8)(脱稿日 2011.5.16)〔連絡先： †920-8641 石川県金沢市宝町 13-1 金沢大学 脳神経外科 毛利正直] [Address correspondence: Masanao MoHRI, M.D., Department of Neurosurgery, Graduate School of Medical Science, Kanazawa University, 13-1 Takara-machi, Kanazawa, Ishikawa 920-8641, Japan] 


\section{はじめに}

未破裂腮動脈瘤に対する瘤内コイル塞栓術の有用性が報 告され2339)10), adjunctive technique の使用により多くの 症例で治療が行われるようになってきている778).

われわれは未破裂脳動脈瘤に対して瘤内コイル塞栓術を 行う際に塞栓率を上げる目的で瘤内に 2 本のマイクロカ テーテルを留置するダブルマイクロカテーテル法を使用し て治療を行い, その治療成績について検討を行った.

対

2006 年 10 月から 2009 年 12 月の期間に, 当施設で瘤内 コイル塞栓術を行った未破裂脳動脈瘤の 30 例を対象とし
た. 年齢は 29 歳から 77 歳 (平均年齢 59.7 歳)で, 男性 8 例, 女性 22 例であった(Table 1)。瘤の大きさは最大径 10 $\mathrm{mm}$ 未満を small 瘤, $10 \mathrm{~mm}$ 以上を large 瘤とした。 small 瘤が 23 例で large 瘤は 7 例であった，瘤の澒部は 4 mm未満を narrow neck, $4 \mathrm{~mm}$ 以上を wide neck とした. narrow neck が 14 例で wide neck が16例であった. 治 療の 3 日前からバイアスピリン $100 \mathrm{mg} /$ 日を投与し, 全身 麻酔下に治療を行い術中はシースを留置したのちにへパリ ンを投与して activated clotting time を投与前の 2 倍以上 に延長させ，術後 48 時間はアルガトロバンを持続投与し た，術中の手技を瘤内に留置したマイクロカテーテルの本 数により, 1 本留置して行った場合にシングルマイクロカ テーテル法(シングルカテ法), 2 本留置して行った場合に

Table 1 Summary of the 30 patients with 30 aneurysms

\begin{tabular}{|c|c|c|c|c|c|c|c|c|c|}
\hline $\begin{array}{l}\text { Case } \\
\text { No. }\end{array}$ & $\begin{array}{l}\text { Age (y) } \\
\text { Sex }\end{array}$ & Location & $\begin{array}{l}\text { Intraaneurysmal } \\
\text { microcatheter }\end{array}$ & $\begin{array}{l}\text { Balloon } \\
\text { assisted }\end{array}$ & $\begin{array}{c}\text { Size of } \\
\text { aneurysm }(\mathrm{mm})\end{array}$ & $\begin{array}{l}\text { Size of neck } \\
(\mathrm{mm})\end{array}$ & L/S ratio & $\begin{array}{l}\text { VER } \\
(\%)\end{array}$ & Complications \\
\hline 1 & $40, M$ & IC paraclinoid & single & - & $3.81 / 2.72 / 3.63$ & 3.69 & 1.40 & 28.9 & - \\
\hline 2 & $49, M$ & Acom & single & - & $4.30 / 2.93 / 3.32$ & 2.50 & 1.46 & 27.8 & - \\
\hline 3 & $45, F$ & IC paraclinoid & single & + & 4.39/3.61/4.01 & 2.58 & 1.22 & 24.4 & - \\
\hline 4 & $62, M$ & VA-PICA & single & - & $4.48 / 2.90 / 3.75$ & 2.49 & 1.54 & 22.7 & - \\
\hline 5 & $29, M$ & IC paraclinoid & single & - & $4.69 / 3.19 / 3.43$ & 2.61 & 1.47 & 21.5 & - \\
\hline 6 & $52, M$ & Acom & single & + & $5.95 / 4.01 / 3.55$ & 3.99 & 1.68 & 20.8 & - \\
\hline 7 & $70, F$ & MCA & single & - & $6.04 / 5.30 / 4.37$ & 4.01 & 1.38 & 24.6 & - \\
\hline 8 & $50, F$ & ICPC & single & - & $6.15 / 5.08 / 4.10$ & 3.00 & 1.50 & 22.7 & - \\
\hline 9 & $64, M$ & Acom & single & - & $6.20 / 5.60 / 5.17$ & 4.76 & 1.20 & 21.9 & - \\
\hline 10 & $61, F$ & ICPC & single & - & $6.59 / 4.34 / 3.90$ & 2.67 & 1.52 & 17.2 & - \\
\hline 11 & $45, F$ & IC paraclinoid & single & + & $7.35 / 6.24 / 5.77$ & 4.75 & 1.27 & 22.8 & - \\
\hline 12 & $70, F$ & BA-SCA & single & - & $7.64 / 5.05 / 5.70$ & 4.50 & 1.51 & 21.9 & - \\
\hline 13 & $68, F$ & IC paraclinoid & single & + & 7.76/4.86/5.10 & 4.86 & 1.60 & 20.6 & - \\
\hline 14 & $71, F$ & Acom & single & - & $8.17 / 4.81 / 4.72$ & 5.60 & 1.73 & 12.5 & - \\
\hline 15 & $65, M$ & MCA & single & + & $10.28 / 5.33 / 5.65$ & 3.34 & 1.93 & 22.8 & - \\
\hline 16 & $73, F$ & ICPC & single & + & 10.96/10.75/7.73 & 6.89 & 1.42 & 20.9 & - \\
\hline 17 & $62, F$ & IC paraclinoid & single & + & $11.23 / 4.57 / 4.63$ & 4.54 & 2.46 & 15.1 & TIA \\
\hline 18 & $57, F$ & ACA & single & - & $11.74 / 7.07 / 7.36$ & 2.69 & 1.66 & 19.7 & - \\
\hline 19 & $64, F$ & BA-SCA & double & + & $5.45 / 3.99 / 4.92$ & 4.75 & 1.37 & 25.4 & - \\
\hline 20 & $55, F$ & IC paraclinoid & double & - & $6.77 / 4.66 / 4.66$ & 3.19 & 1.45 & 33.9 & - \\
\hline 21 & $60, F$ & IC bifurcation & double & - & $7.32 / 6.24 / 7.12$ & 5.63 & 1.17 & 27.4 & - \\
\hline 22 & $33, \mathrm{M}$ & ICPC & double & - & $7.97 / 4.45 / 4.95$ & 3.75 & 1.79 & 30.6 & - \\
\hline 23 & $67, F$ & ICPC & double & - & $8.20 / 7.70 / 7.50$ & 7.16 & 1.09 & 21.1 & - \\
\hline 24 & $64, F$ & IC paraclinoid & double & + & $8.88 / 7.47 / 7.44$ & 6.06 & 1.19 & 29.2 & - \\
\hline 25 & $69, F$ & IC paraclinoid & double & - & $9.05 / 5.42 / 5.10$ & 3.25 & 1.77 & 24.5 & - \\
\hline 26 & $65, F$ & IC paraclinoid & double & - & $9.35 / 8.20 / 7.94$ & 5.04 & 1.18 & 21.2 & - \\
\hline 27 & $65, F$ & IC paraclinoid & double & + & $9.39 / 8.26 / 7.09$ & 6.95 & 1.32 & 26.1 & - \\
\hline 28 & $72, F$ & ICPC & double & - & 17.0/12.8/15.2 & 4.45 & 1.33 & 18.3 & - \\
\hline 29 & $77, F$ & IC cavernous & double & + & 17.0/14.1/14.3 & 8.12 & 1.21 & 25.4 & - \\
\hline 30 & $68, F$ & IC paraclinoid & double & - & $20.22 / 15.07 / 15.27$ & 3.90 & 1.34 & 18.7 & - \\
\hline
\end{tabular}

$\mathrm{ACA}=$ anterior cerebral artery; Acom=anterior communicating artery; BA-SCA=basilar artery-superior cerebellar artery; $I C=$ internal carotid artery; L/S ratio=long aneurysmal diameter/short aneurysmal diameter ratio; MCA= middle cerebral artery; VA-PICA $=$ vertebral artery-posterior inferior cerebellar artery; $\mathrm{VER}=$ volume embolization ratio; ICPC =internal carotid artery posterior communicating artery 
Table 2 Aneurysmal morphology and volume embolization ratio

\begin{tabular}{lccc}
\hline \multirow{2}{*}{$\begin{array}{l}\text { Aneurysmal } \\
\text { morphology }\end{array}$} & \multicolumn{2}{c}{ Volume embolization ratio (\%) } & \multirow{2}{*}{ P value } \\
\cline { 2 - 3 } & single & double & \\
\hline L/S ratio $\geqq 1.5$ & $19.7 \pm 3.4$ & $27.6 \pm 4.3$ & 0.0139 \\
L/S ratio $1.5>$ & $24.6 \pm 2.9$ & $24.7 \pm 4.9$ & 0.9574 \\
\hline
\end{tabular}

$\mathrm{L} / \mathrm{S}$ ratio $=$ long aneurysmal diameter/short aneurysmal diameter ratio

ダブルマイクロカテーテル法(ダブルカテ法)として比較し た.ダブルカテ法は親動脈の径が太く 2 本のマイクロカ テーテルを瘤まで安全にアプローチでき, 瘤内のスペース が広く 2 本のマイクロカテーテルを安全に留置できると判 断した症例に選択した。動脈硬化の強い症例, 瘤から分岐 した血管の温存のために分岐血管にマイクロカテーテルの 留置を行った症例やバルーン支援を併用した症例のなかで 瘤内に 2 本のマイクロカテーテルが安全に留置できないと 判断した症例は除外した。 シングルカテ法群は 18 例で, ダブルカテ法群は 12 例であった。 バルーン支援を併用し た症例は 11 例あり，それぞれシングルカテ法群で 7 例, ダブルカテ法群で 4 例であった. 瘤内塞栓には Guglielmi detachable coil (GDC; Boston Scientific)を使用した. フ レーミングには主にGDC 18-2D, GDC 18-360，GDC 10-2D, GDC 10-360使用し，順に GDC 10-Soft 2D SR, GDC 10-UltraSoft を使用した. 動脈瘤の体積は脳血 管撮影の 3D-rotation angiography から 3 方向の長さを測 定し計算した. 瘤内に留置したコイルの体積はコイルの径 と長さから計算し, 瘤内塞栓率(volume embolization ratio: VER) として, 動脈瘤の体積に対するコイルの体積 比を計算した. シングルカテ法群とダブルカテ法群の治療 成績を VER 㧍よび出血性合併症と虚血性合併症について 比較した. 統計学的解析は, unpaired t-testまたは Mann-Whitney's U testによって行い, $\mathrm{P}<0.05$ をもて 統計学的に有意とした.

\section{結果}

動脈瘤の大きさは最大径でシングルカテ法群では $7.10 \pm$ $2.53 \mathrm{~mm}$, ダブルカテ法群では $10.55 \pm 4.74 \mathrm{~mm}$ であった $(\mathrm{P}<0.05)$ ） ネックの大きさはシングルカテ法群では 3.86 $\pm 1.25 \mathrm{~mm}$ で, ダブルカテ法群では $5.19 \pm 1.62 \mathrm{~mm}$ であっ た $(\mathrm{P}<0.05)$. 動脈瘤の塞栓率については, シングルカテ 法群全例の VER は $21.6 \pm 3.9 \%$ で, ダブルカテ法群全例 の VER は $25.2 \pm 4.8 \%$ であり有意差を認めた $(\mathrm{P}<0.05)$. その中でバルーン支援を行わずにシングルカテ法で治療し た群の VER は $21.9 \pm 4.6 \%$ で，バルーン支援を行わずに ダブルカテ法で治療した群の VER は $24.5 \pm 5.7 \%$ であっ た $(\mathrm{p}=0.300)$ 。またバルーン支援を併用してシングルカテ
法で治療した群の VER は $21.1 \pm 3.0 \%$ で，バルーン支援 を併用してダブルカテ法で治療した群の VER は $26.5 \pm$ $1.8 \%$ であり有意差を認めた $(\mathrm{p}<0.05)$ ．動脈瘤の大きさ別 にみた塞栓率は small 瘤群ではVER は $23.9 \pm 4.6 \%$ で, large 瘤群では VER は $20.1 \pm 3.3 \%$ であり $(\mathrm{P}=0.054)$, ネッ クの大きさ別にみた塞栓率は narrow neck 群では VER は $22.4 \pm 3.7 \%$ で, wide neck群ではVERは23.6 $55.5 \%$ であっ た $(\mathrm{p}=0.504)$. 動脈瘤の形状を動脈瘤の長径と短径の比か ら長径と短径の比が大きい動脈瘤 (長径 / 短径 $\geqq 1.5)$, 長 径と短径の比が小さい動脈瘤 (長径 / 短径 $<1.5)$ に分類し てVERを比較した(Table 2). 長径と短径の比が小さい 動脈瘤はシングルカテ法群とダブルカテ法群ではVER は 有意差がみられなかった，長径と短径の比が大きい動脈瘤 ではシングルカテ法群では塞栓率が有意に低下した。 術中 の虚血性合併症はシングルカテ法群で麻酔覚醒直後に一過 性脳虚血発作が 1 例に出現したが, 術中の出血性合併症は いずれの方法でも出現しなかった.

\section{症例呈示(Fig. 1)}

〈Case 24〉64 歳, 女性.

頭痛の精查で発見された無症候性の左傍前床突起内澒動 脈瘤で，大きさは $8.88 \mathrm{~mm} \times 7.47 \mathrm{~mm} \times 7.44 \mathrm{~mm}$, 頝部は $6.06 \mathrm{~mm}$ であった，右大腿動脈に $6 \mathrm{Fr}$ シースと左大腿動 脈に $5 \mathrm{Fr}$ シースを留置し, 左内頚動脈に $6 \mathrm{Fr}$ Envoy MPD (Cordis)と 5Fr Envoy STR (Cordis)を誘導しそれ ぞれヘパリン加厤生食で灌流した. 5Fr Envoyから HyperGlide $4 \mathrm{~mm} \times 15 \mathrm{~mm}$ （ev3）を動脈瘤の頚部に留置 したのちに, 6Fr Envoy から 1本目のマイクロカテーテ ルとして Excelsior 1018 pre-shaped J (Boston Scientific) を瘤内の inflow zoneから回り込んだ部位に留置して，2 本目のマイクロカテーテルとして Excelsior SL-10 preshaped 45 (Boston Scientific)を1本目のマイクロカテー テルより瘤内の手前に誘導した. HyperGlide を inflation させて瘤内にコイルを誘導させ,コイル留置後に HyperGlide を deflation してコイルの親動脈への逸脱がな いことを確認しコイルを detach した. ファーストコイル は Excelsior 1018 pre-shaped J から GDC 18-2D $7 \mathrm{~mm}$ $\times 30 \mathrm{~cm}$ を留置し detachする前に Excelsior SL-10 pre- 


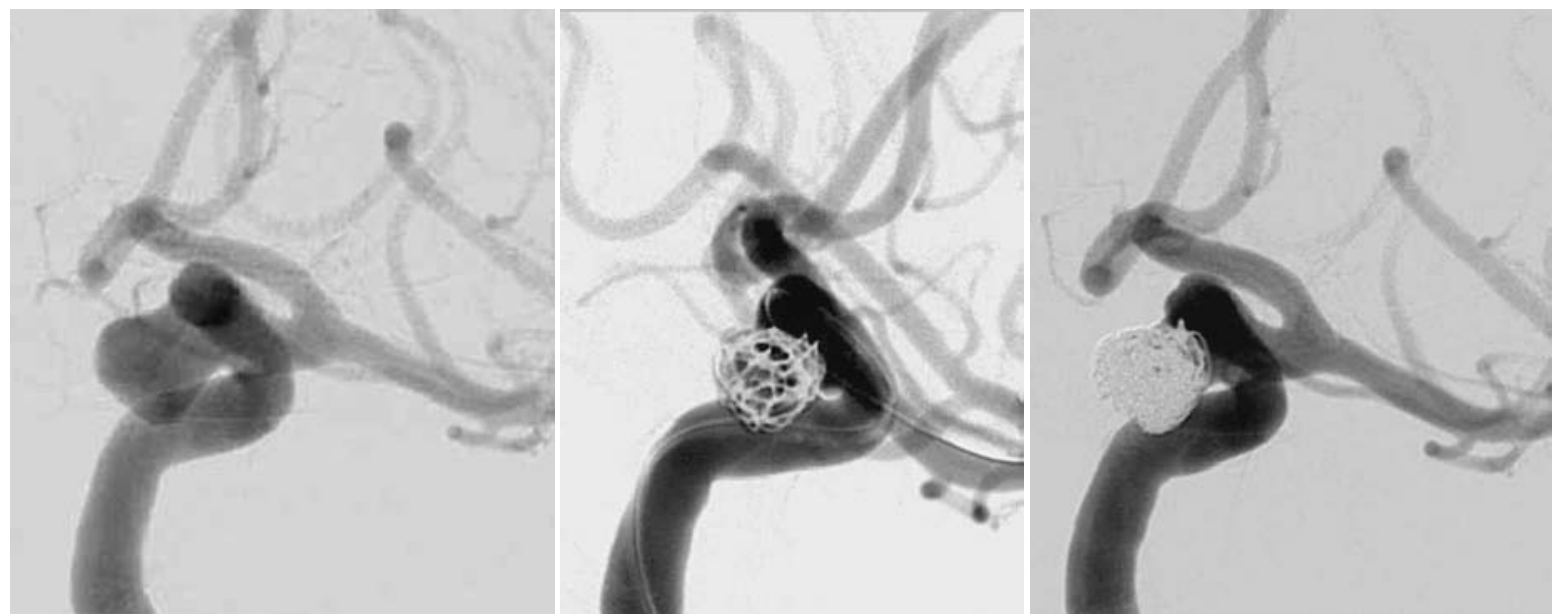

Fig. 1 Case 24, a 65-year-old-woman. left: Left internal carotid angiogram, right anterior oblique view, shows a paraclinoid ICA aneurysm. center. Two coils (GDC 18-2D; $7 \mathrm{~mm} \times 30 \mathrm{~cm}$, GDC 10-Soft 2D SR $5 \mathrm{~mm} \times 8 \mathrm{~cm}$ ) are being deployed via 2 microcatheters. More stable coil configuration has been achieved with the addition of the second coil inserted through the second microcatheter. right: After depositing 13 coils (18 type coil total length; $30 \mathrm{~cm}$ and 10 type coil total length; $88 \mathrm{~cm}$ ), the 2 microcatheters were removed. Satisfactory aneurysmal occlusion was achieved.

shaped J から GDC 10-Soft 2D SR $5 \mathrm{~mm} \times 8 \mathrm{~cm}$ を 1 本 目のコイルが移動しないことを確認しながら留置した. 2 本目のコイルを detach し, 以後は順にすでに留置してい るコイルが安定していることを確認しながら塞栓を行っ た. 18 type のコイルを $30 \mathrm{~cm}$ と 10 typeのコイルを $88 \mathrm{~cm}$ 留置してVERは $29.2 \%$ であった。

\section{考察}

未破裂脳動脈瘤の治療として, 血管内治療技術の進歩に 伴い瘤内コイル塞栓術が多くの症例で行われるようになり その安全性と有用性が報告されている2339910)。しかし塞栓 術には術中にすでに detach したコイルが次のコイルの挿 入時に動く危険性があり，また瘤内の塞栓が不完全な場合 には再開通率が高く, 長期的予後を考えるうえでの問題点 とされている. これらの問題点を克服するために, 瘤内に 2 本のマイクロカテーテルを留置するダブルカテ法を使用 してその有用性について検討した。

コイル塞栓術の塞栓率は術後の長期的な安定性にVER が血管撮影上の塞栓率よりも客観的な指標になることが報 告されており ${ }^{11)}$, 今回はシングルカテ法とダブルカテ法の 塞栓率の評価をVERで行った。

瘤内コイル塞栓術に不向きな䅡部の広い動脈瘤に対し て, adjunctive technique としてダブルカテ法以外にバ ルーン支援による remodeling technique ${ }^{7)}$ や自己拡張型ス テントの支援による塞栓術 ${ }^{6}$ が, 動脈瘤から親動脈へのコ イルの逸脱を防ぐ方法として有用な方法として報告されて いる. バルーン支援による remodeling technique ではコ
イルの親動脈への逸脱は防げるが，大きめの動脈瘤では瘤 内を均一に塞栓することは難しい，そこで 2 本のマイクロ カテーテルを瘤内に留置し塞栓の状況に応じてコイルを留 置するマイクロカテーテルを選択できることが塞栓率の向 上につながると考え, ダブルカテ法とシングルカテ法での 瘤内塞栓術の治療成績について比較した。

今回われわれが行ったダブルカテ法は，塞栓術中の瘤内 でのコイルの安定性と瘤内の塞栓率を上げることとを目的 として行った. 1 本目のマイクロカテーテルから留置した コイルを detachする前に 2 本目のマイクロカテーテルか らコイルを留置して1本目のコイルが不安定な動きをして detach 直後の位置から移動しないこと形状が変化しない ことを確認して 2 本のコイルのうち 1 本のコイルを detach した。 また瘤内の塞栓率を上げる目的で均一な塞 栓ができるように 2 本のマイクロカテーテルの位置を工夫 した. 具体的には治療の最終段階にはマイクロカテーテル が inflow zone から逸脱することが予想されるため, 1 本 のマイクロカテーテルは通常の位置に留置して, 他方のマ イクロカテーテルは inflow zone から離れた位置に留置し た。途中で loose な空間ができてきた場合にはマイクロカ テーテルをその部位に留置し直した.

これまでに瘤内コイル塞栓術に瘤内に 2 本のカテーテル を留置する方法は, 頚部が広いあるいは脳動脈㼡から重要 な血管が分岐している症例に至適で安全な方法として報告 されている ${ }^{14) 5)}$. 今回の塞栓率の比較ではダブルカテ法群 の動脈瘤は大きく, 頚部も広く塞栓術には不向きな動脈瘤 であったが有意に高い塞栓率が得られた，その中でバルー 
ン支援併用の有無を考慮して塞栓率を検討すると, バルー ン支援なしでダブルカテ法を行った群の塞栓率とバルーン 支援なしでシングルカテ法を行った群の塞栓率を比較する と有意差はなかったが，バルーン支援を併用したダブルカ テ法群の塞栓率はバルーン支援を併用したシングルカテ法 群の塞栓率より有意に高い結果となった。 バルーンを併用 したダブルカテ法がより効果がある可能性があるが, 今後 は症例数を増やして, バルーン支援の有無も加味したダブ ルカテ法の効果を検討したい.

ダブルカテ法がどのような動脈瘤に有効かを形状に注目 して検討した，長径と短径の比が小さい動脈瘤はシングル カテ法群でもダブルカテ法群でも同様に安定した塞栓率を 得られたが, 長径と短径の比が大きい動脈瘤ではシングル カテ法群では塞栓率が有意に低下したことより, 長径と短 径の比が大きいと塞栓術中に疎な空間が出現することがあ り，途中で疎な空間ができるとシングルカテ法ではその部 分に密に塞栓することが困難となることが原因と考えられ た、ダブルカテ法ではそのような欠点を補うことができる ため特に長径と短径の比が大きな形状の動脈瘤に有効と考 えられた。

ダブルカテ法の不利な点はシングルカテ法に比べて手技 が複雑になることであり, 特に 2 本のコイルが絡まり回収 困難になる可能性があり注意が必要である. 今回の方法で は 2 本のマイクロカテーテルから同時にコイルを留置する のではなく 1 本ずつコイルを留置して行う方法をとったた めコイルが絡んで回収困難となることはなかったが手技上 の留意すべき点である．また 2 本のマイクロカテーテルの セカンドマーカーが重なり区別しにくいことも予想される が瘤内のマイクロカテーテルの先端位置が離れていること 透視の角度をわずかに変えることでセカンドマーカーの区 別は困難ではなかった．ダブルカテ法の手技に伴う虚血性 合併症掞よび出血性合併症もみられなかった点からも, シ ングルカテ法と同様の安全性と考えられた。

今回の検討で長径と短径の比が大きな脳動脈瘤ではシン グルカテ法では均一な塞栓が難しいことがあり, 今後はこ のような動脈瘤にダブルカテ法を用いることにより安定し て塞栓率を高めることができるかを注目したい.

\section{結語}

未破裂胹動脈瘤に対して術中のコイルの安定性と塞栓率
を上げることを目的に瘤内に 2 本のマクロカテーテルを留 置するダブルカテ法について検討した. ダブルカテ法で特 に長径と短径の比が大きな形状の動脈瘤に対する塞栓率を 上げることができたこと，手技は複雑になるものの合併症 の増加もみられなかったことより, 有用で安全な方法と考 えられた。

\section{文献}

1) Baxter BW, Rosso D, Lownie SP: Double microcatheter technique for detachable coil treatment of large, widenecked intracranial aneurysms. AJNR Am J Neuroradiol 19: $1176-1178,1998$

2) Gonzalez N, Murayama Y, Nien YL, et al: Treatment of unruptured aneurysms with GDCs: Clinical experience with 247 aneurysms. AJNR Am J Neuroradiol 25: 577583, 2004

3) Johnston SC, Zhao S, Dudley A, et al: Treatment of unruptured cerebral aneurysms in California. Stroke 32: 597-605, 2001

4) Kai Y, Hamada JI, Morioka M, et al: Double microcatheter technique for endovascular coiling of wide-neck aneurysms using a new guiding device for the transcarotid approach: technical note. Neuroradiology 47: 73-77, 2005

5) Kwon OK, Kim SH, Kwon BJ, et al: Endovascular treatment of wide-necked aneurysms by using two microcacheters: Techniques and outcomes in 25 patients. AJNR Am J Neuroradiol 26: 894-900, 2005

6) Mocco J, Snyder KV, Albuquerque FC, et al: Treatment of intracranial aneurysms with the Enterprise stent: a multicenter registry. J Neurosurg 110: 35-39, 2009

7) Pierot L, Spelle L, Leclerc X, et al: Endovascular treatment of unruptured intracranial aneurysms: Comparison of safety of remodeling technique and standard treatment with coils. Radiology 251: 846-855, 2009

8) Ross IB, Dhillon GS: Balloon assistance as a routine adjunct to the endovascular treatment of cerebral aneurysms. Surg Neurol 66: 593-602, 2006

9) Roy D, Milot G, Raymond J: Endovascular treatment of unruptured aneurysms. Stroke 32: 1998-2004, 2001

10) Standhardt H, Boecher-Schwarz H, Gruber A, et al: Endovascular treatment of unruptured intracranial aneurysms with Guglielmi Detachable Coils. Short- and longterm results of a single-center series. Stroke 39: 899-904, 2008

11) Tamatani $\mathrm{S}$, Ito $\mathrm{Y}$, Abe $\mathrm{H}$, et al: Evaluation of the stability of aneurysms after embolization using detachable coils: correlation between stability of aneurysms and embolized volume of aneurysms. AJNR Am J Neuroradiol 23: 762-767, 2002 